\section{Children's stimulus selection as a function of auditory stimulus complexity}

ANN W. DUKE,' Universitl of Nebraska. lincoln, Nebr. 68508, and GARY R. GUIIICKSON, Institute for Juvenile

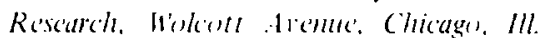
oush 2

Forty-eight preschool children were given 80 trials on a stimulus-selection task in which they could choose one of four auditory stimuli by moving a lever in one of four directions. The four stimuli varied in complexity defined by: (1) number of components in each stimulus; (2) dissimilarity of the components; and (3) the pattern of similar and dissimilar components. Analy'ses of selections pooled across Ss indicated that: (1) Ss preferred a stinulus with components of two frequencies to a stimulus with components of the same frequency: (2) Ss preferred a stimulus with components alternating in their frequency characteristics to a stimulus with the first two components of one frequency and the last two of another frequency: and (3) on the last trial block, $S s$ preferred a stimulus with four components to a stimulus with two components. Analyses of selections for individual Ss, however, indicated that: (1) few Ss showed significant selection preferences, and (2) when significant preferences were found, there were often some Ss preferring a less complex stimulus. The results were discussed within the framework of Berlyne's (1960) formulation.

According to Berlyne's (1960) formulation, selection behavior is a direct function of stimulus complexity. The degree of complexity varies directly with the number of stimulus components and with the dissimilarity among these components. In addition, the degree of complexity varies inversely with the extent to which components are responded to as a unit.

In the present study, the variables identified by Berlyne as determinants of complexity are manipulated and their relationship to children's selection of auditory stimuli is investigated. On each trial, preschool children selected one of four auditory stimuli for presentation. The stimuli differed in number, similarity, and pattern of components. Two stimuli differed in number of components, two differed in their component similarity (defined in terms of the auditory frequency of the components), and two differed in the pattern or arrangement of their components, which were the same in number and frequency. This last stimulus pair was included to determine the relationship between stimulus selection and Berlyne's third variable, the extent to which stimulus components are organizable into units. While it is not clear how to define a component "unit," a stimulus in which each component differs from the immediately preceding component could perhaps be considered to have more component units than does a stimulus in which one or more of its components is identical to the immediately preceding component; i.e., a stimulus involving greater change among its components might be considered to have more units than a stimulus with fewer component changes.

\section{SUBJECTS}

The Ss were 24 males and 24 females attending the Preschool Laboratory of the Institute of Child Behavior and Development at the University of lowa. In age, Ss ranged from 48 months to 63 months, with a median of 58 months.

\section{APPARATUS AND STIMULI}

The apparatus consisted of a vertical stimulus panel with a horizontal response panel projecting from its base. A light (General Electric No. 47 lamp behind a yellow-faceted lens) was mounted in the center of the stimulus panel. A 3-in. lever that could be moved in any one of four directions (forward, backward, left, and right) was mounted in the center of the response panel. A picture of a hand was located on the right side of the response panel.

The components of the four stimuli used in the experiment were monophasic spike waves. The oscillator producing the stimuli contained a General Electric No. 2N2160 unijunction transistor and was attached to a speaker mounted on the back of the vertical stimulus panel. At a point approximating the top of S's head, the sound pressure level was $56 \mathrm{~dB}$.

Stimulus A consisted of two 1,000-msec $600-\mathrm{Hz}$ tones. Stimulus B consisted of four $500-\mathrm{msec} 600-\mathrm{Hz}$ tones. Stimulus C consisted of four 500 -msec tones, with the first two tones being $600 \mathrm{~Hz}$ and the second two being $350 \mathrm{~Hz}$. Stimulus D consisted of four $500-\mathrm{msec}$ tones presented in the following order: $600 \mathrm{~Hz}, 350 \mathrm{~Hz}$, $600 \mathrm{~Hz}$, and $350 \mathrm{~Hz}$. The intercomponent interval was $15 \mathrm{msec}$.

\section{PROCEDURE}

Each $\mathrm{S}$ was brought individually to the experimental room and seated in front of the apparatus. He was then told that when the stimulus light was off, he was to keep his right hand on the hand picture, and when the light came on, he was to use his right hand to move the lever in any one of the four directions. The $\mathrm{E}$ demonstrated the four possible responses and presented the auditory stimulus associated with each response. The pairing of stimuli and response positions was counterbalanced using a Latin-square design, so that each stimulus was associated with each possible response for one-fourth of the Ss.

Each $S$ was presented 80 trials with a 4-sec intertrial interval.

\section{RESULTS}

The observed total frequencies of selection for Stimuli A, B, C, and D were $715,787,1,055$, and 1,283 , respectively. A chi square applied to these frequencies was significant $\left(\chi^{2}=211.78\right.$, df $\left.=3, p<.01\right)$. Subsequent chi-square comparisons were performed for Stimuli $A$ and $B\left(\chi^{2}=3.45\right.$, $\mathrm{df}=1, \quad \mathrm{p}>.05), \quad$ Stimuli $\mathrm{B}$ and $\mathrm{C}$ $\left(\chi^{2}=38.99, \mathrm{df}=1, \mathrm{p}<.01\right)$, and Stimuli $C$ and $D\left(\chi^{2}=22.24, d f=1, p<.01\right)$.

The mean cumulative response frequency for each of the four stimuli over the 80 trials is presented in Fig. 1. A chi square applied to the selection frequencies for the first block was significant $\left(\chi^{2}=15.11, \mathrm{df}=3, \mathrm{p}<.01\right)$. Subsequent chi-square analyses indicated no significant different in the selection of Stimuli $A$ and $B\left(\chi^{2}=.086, d f=1\right.$, $p>.05)$ and Stimuli $C$ and $D\left(x^{2}=.03\right.$, $\mathrm{df}=1, \mathrm{p}>.05)$. The comparison between Stimuli $B$ and $C$, however, was significant $\left(\chi^{2}=8.82\right.$, df $\left.=1, p<.01\right)$. To determine if there were significant differences in the initial selection frequencies of the four stimuli, a chi-square analysis was applied to these frequencies for the first 10 trials. This chi square was not significant $\left(x^{2}=1.77, \quad \mathrm{df}=3, \mathrm{p}>.05\right.$, with

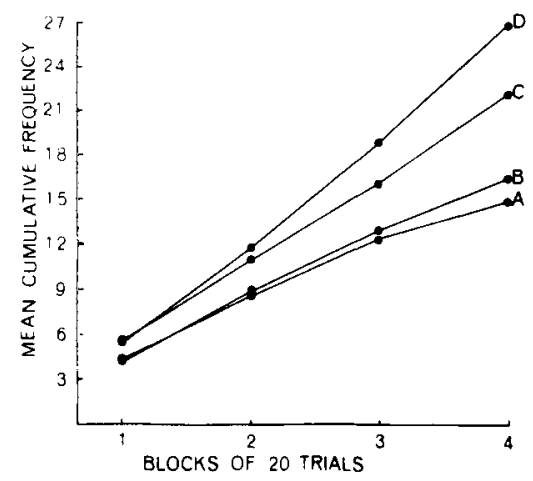

Fig. 1. Cumulative response frequency as a function of trials for the four stimuli. 
frequencies of $93,94,107$, and 90 for Stimuli A, B, C, and D, respectively).

A chi square applied to the selection frequencies for the last trial block was significant $\left(\chi^{2}=167.57, \mathrm{df}=3, \mathrm{p}<.01\right)$. Subsequent comparisons on the last trial block indicated that: (1) Stimulus B was selected significantly more often than Stimulus A $\left(\chi^{2}=7.53, \mathrm{df}=1, \mathrm{p}<.01\right)$; (2) Stimulus $C$ was selected significantly more often than Stimulus B $\left(\chi^{2}=30.40\right.$, $\mathrm{df}=1, \mathrm{p}<.01$ ); and (3) Stimulus D was selected significantly more often than Stimulus C $\left(\chi^{2}=12.42, \mathrm{df}=1, \mathrm{p}<.01\right)$.

Since the preceding analyses involved group scores, chi-square analyses were also performed for each $S$ to determine the extent to which the group analysis represented effects for individuals. Over the 80 trials, the chi-square analysis for 22 Ss (14 males and 8 females) was significant $(p \leqslant .05)$. Subsequent comparisons for the stimulus pairs resulted as follows: (1) For the A-B comparison, the chi square of $6 \mathrm{Ss}$ was significant $(p \leqslant .05)$. However, half of these 6 Ss selected Stimulus A (the less complex) more often than Stimulus B. The nonsignificant A-B group comparison, then, conforms with the majority of the individual Ss. (2) For the B-C comparison, the chi square of $13 \mathrm{Ss}$ was significant $(p \leqslant .05)$. Of these 13 Ss, 4 selected Stimulus B (the less complex) more often than Stimulus C. Thus, the significant B-C group comparison conforms with a significant effect for less than $20 \%$ of the Ss. (3) For the C-D comparison, the chi square for 6 Ss was significant $(p \leqslant .05)$. All 6 Ss selected Stimulus D (the more complex) more often than Stimulus C. While no significant individual effects are in opposition to the group's significant preference for Stimulus D, the group preference is supported by significant individual preferences of only $16.67 \%$ of the Ss.

Chi-square analyses were also performed on the selection frequencies of individuals for Trial Blocks 1 and 4. For Trial Block 1 , the chi square for $8 \mathrm{Ss}$ ( 5 males and 3 females) was significant $(p \leqslant .05)$. For the last trial block, the chi square for $15 \mathrm{Ss}(10$ males and 5 fernales) was significant $(p \leqslant .05)$. No stimulus comparisons were performed for these blocks since the expected cell frequencies for many individuals would be quite small. Thus, the significant group chi squares are supported by relatively few individual analyses (16.67\% of the Ss for Block 1 and $31.25 \%$ for Block 4).

\section{DISCUSSION}

In the present study, the group data support Berlyne's (1960) formulation. In the final trial block, all three variables-number, dissimilarity, and pattern or change of components-did significantly affect the choice responses. A stimulus of four components (Stimulus B) was selected more often than was a stimulus of two components (Stimulus A). A four-component stimulus with two component frequencies (Stimulus C) was selected more often than a four-component stimulus with one frequency (Stimulus B). Finally, in the comparison of the stimuli with four components and two frequencies, the stimulus with the greater amount of change (Stimulus D, in which the frequencies alternated) was selected more often than was Stimulus C, in which the frequencies were blocked. The analysis of all 80 trials further supports the relationship between stimulus selection and the variables, dissimilarity and pattern of components. However, there was no significant relationship between stimulus selection and component number across all trials.

Although the group data support Berlyne, the analysis of the data for individual Ss give the formulation little support. The percentage of Ss showing selection differences as a function of the four stimuli ranged from 45.83 across all 80 trials to 16.67 in the first trial block. At no time did the majority of the Ss demonstrate significant differences in the selection of the four stimuli. Paired comparisons among the stimuli on all 80 trials gave little support to the hypothesis that the variables, number, dissimilarity, and pattern of components, affect the choice behavior of the individuals in this study. Only $12.5 \%$ of the Ss were influenced by the number manipulation, with half of these Ss, in direct opposition to the formulation, preferring the less complex stimulus. For approximately $27 \%$ of the Ss, there was a significant relationship between stimulus selection and component dissimilarity. However. approximately $8 \%$ of all Ss and almost $31 \%$ of Ss showing a significant preference selected the less complex stimulus more often than the more complex stimulus. For the comparison involving stimulus change, only $16.67 \%$ of the $\mathrm{Ss}$ showed a significant preference.

The results of this study, then, do not support the hypothesis that number. dissimilarity, and pattern of components are significant determinants of the selection of auditory stimuli by most individuals. In previous research (e.g., Cantor, Cantor, \& Ditrichs, 1963; Hershenson, Munsinger, \& Kessen, 1965), the results have generally been reported for pooled individuals. In view of the present discrepancy between individual and pooled data, it would seem useful for future investigators to extend our research information by examining both types of data.

In addition, the stimuli in previous research studies (e.g., Cantor et al, 1963: Hershenson, 1964) are visual. This study extends the complexity manipulations to auditory stimuli and provides evidence that the variables relating to stimulus complexity can be clearly defined for such stimuli.

\section{REFERENCES}

BERLYNE, D. E. Conflict, arousal, and curiosity. New York: McGraw-Hill, 1960.

CANTOR, G. N., CANTOR, J. H., \& DITRICHS, R. Observing behavior in preschool children as a function of stimulus complexity. Child Development, 1963, 34, 683-689.

HERSHENSON, M. Visual discrimination in the human newbom. Journal of Comparative \& Physiological Psychology, 1964, 58, 270-276. HERSHENSON, M., MUNSINGER, H., \& KESSEN, W. Preference for shapes of intermediate variability in the newborn human. Science, 1965, 147, 630-631. NOTE

1. Author's address: Department of Educational Psychology and Measurements, Unviersity of Nebraska, Lincoln, Nebr. 68508. 